\title{
An explorative integration of factors causing men's violence against women
}

\begin{abstract}
Despite the great progress in individual disciplines studying men's physical violence against women, the various disciplines have developed much different approaches that by themselves are insufficient for understanding the processes that lead to men's violence against women. Moreover, they also tend to neglect the equally important issue of understanding why some men are not violent toward women. The aim of this work is to integrate former research on socially modifiable factors and therefore does not include theories relating genetics and neurochemistry that may also play an important role. It shows how the psychological approach within criminology can be integrated with the feminist masculinity perspective. The work illustrates that it is both theoretically and methodologically possible, through an integration of previous research, to make hypotheses about under which conditions men are likely to be violent against women, as well as make hypotheses about under what conditions men are unlikely to be violent against women. This study also emphasizes methodologically important non-dichotomous forms where both enabling and reactive conditions are mixed at various levels. Despite the methodological problems, an integrated perspective on men's violence against women is the most promising way forward today.
\end{abstract}

Keywords: integration, hegemonic masculinity, marginalized men, men's violence against women, doing masculinity, figuration
Volume 8 Issue 2 - 2017

Peter M Jansson

Health and Welfare Research, Dalarna University, Sweden

Correspondence: Peter M Jansson, Health and Welfare Research, Dalarna University, Sweden, Tel 0046023-778552, Emailpja@du.se

Received: August 28, 2017| Published: September 13, 2017

\section{An explorative integration of factors causing men's violence against women}

The United Nations ${ }^{1}$ estimates that one in three women has been beaten or sexually abused in their lifetime and that this violence against women (VAW) is present in both highly developed and less developed countries. While men's VAW is one of our greatest social problems, research on VAW is generally polarized. Psychological research tends to explain violence at the individual level and, therefore, does not explain the social contexts that make violence acceptable to some groups. Meanwhile, feminist-oriented masculinity, based on patriarchal theory and structural relationships, theory can, in some forms, explain the power-relations that induce men to act violently. Yet, without a psychological perspective, we cannot explain why only some men are violent. Within feminist research, the sociological tradition has often emphasized socialization processes that make violence acceptable. Again, without a psychological perspective, however, we cannot explain why some men are violent and others are not; and without a power perspective from masculinity studies, we cannot explain how the underlying mechanisms make such socialization possible. Consequently, Brownridge ${ }^{2}$ concludes that despite extensive research, there is currently no single theory that can explain men's VAW. According to Dutton, ${ }^{3,4}$ the lack of integration between approaches may be due to the fact that feminist scholarswhile acknowledging that their research is not monolithic-have mainly studied power and macro-structures and as such have tended to delineate themselves from psychological research that examines offenders suffering from psychological disorders, attachment disorders and shame sensitivity. According to Jordan (2009), those few attempts at integrating research traditions suffer from the fact that they remain disconnected from one other when conducting empirical research. This in turn makes it difficult to unite the different perspectives. Many scholars believe, therefore, that despite great progress in individual disciplines, men's VAW remains as an intractable social problem that requires new approaches that can bridge the lack of integration between disciplines and achieve greater progress in reducing men's VAW. This theoretical work aims to develop new knowledge about how to unite the psychological research (that studies violent men's childhood, the sociological perspective (that studies socialization experiences) with the feminist-oriented masculinity research (that studies how VAW contributes to the reproduction of patriarchal and hegemonic masculinity power structures). This work only study factors that are possible to influence by social interventions and prevention. Genetic, neurochemical and bio-psychiatric factors are therefore excluded. VAW comprises in this paper, only emotional/ reactive violence and violence influenced by patriarchal gender constructs. The typologies used here are abstractions and are used as a heuristic device to generate hypotheses that are intended to become concrete in a later research application.

\section{Why is an integrative approach necessary for an understanding of men's vaw?}

Even though it is common to use an integrative perspective in the social sciences, it is rarely used in studies on VAW. Scholars as Crowell \& Burgess ${ }^{5}$ have however acknowledged the need of to integrating factors operating on various levels. O'Neil \& Harway ${ }^{6}$ have developed an interdisciplinary multi-factor model that integrated biological, macro-societal gender-role socialization and relational variables. Their model describes at various levels many causes of VAW. However, their model is atheoretical as it does not clarify the interactions between factors that contribute to, as well as counteract, VAW. Heise ${ }^{7}$ makes an impressive attempt to clarify the etiology of VAW through an ecological and integrative perspective. But as Ali $\&$ Naylor $^{8}$ state, all efforts are futile if they lack the ability to clarify the causal associations among factors. My own heuristic attempt is influenced by a realist approach, ${ }^{9}$ and is designed to move away from the focus on probability in previous studies as Heise, ${ }^{7}$ and put a greater emphasis on how VAW emerges as a result of the interplay between enabling, as well as counteracting factors at various levels. 
One influential integrational approach has been the intergenerational transmission of violence (IGT).$^{10}$ It aims to explain the link between children's witnessing interparental aggression, socialization-factors and VAW. However, this perspective does not link these factors to societal power structures, such as socioeconomic class position and ethnicity that structure the preconditions for family violence. A fuller explanation of men's VAW requires new theoretical models that integrate research from various disciplines that at first glance appear to be incommensurable. Models that integrate interdisciplinary explanations of VAW have a key advantage since they inform us about how conditions at different levels tend either to restrict or to enable men's VAW as a causal outcome. While the benefits of a realistic interdisciplinary perspective are great, ${ }^{9}$ it is easy to understand that there are difficulties in trying to include several different theories and perspectives in a single model. Furthermore, this effort will not explain why some men-despite exhibiting experiences and characteristics that relate to VAW-do not use VAW. In creating an integrative model, three established approaches for studying violent men has been selected.

a. The masculinity approach within feminism that focuses on men's violence as part of their doing masculinity (i.e. self-construction of their masculinity).

b. The gender-socialization approach.

c. The psychological approach that focuses on violent childhood experiences and/or the witnessing of interparental violence.

This paper has, according to an attempt to integrate socially modifiable factors, delineated itself from the growing body of biological research on genetic propensities and neurobiological factors, as well as the significance of dysfunctional relationships to deviant peers, but will consider them for a subsequent empirical application. Even though some studies have concluded that biological factors have influence on the behavior of violent men, these are not sufficient conditions for men to be violent. Not all men with these biological traits automatically become violent. Thus, this article theorizes more about the necessary than about the sufficient conditions. Each approach has advantages and disadvantages, so an integrative approach can potentially utilize the advantages of all three approaches, while overcoming the disadvantages of each approach. The masculinity approach is abstract and focuses inter alia on socioeconomic resources and, consequently, cannot explain why some people who belong to a marginalized group still do not become violent. Meanwhile, empirically-oriented psychological research and socialization-oriented research concentrate on processes in the family and, therefore, lack macro-theoretical framing. It is necessary to include the social setting and power relations, to show why groups that have a greater risk of being violent can emerge in the first place. Thus, by themselves, none of these approaches are satisfactory, because their explanations tend to be reductionist. Therefore, if we are to move forward with a fuller explanation, then we need to integrate the three approaches. One aim is to construct a model that integrates the psychological perspective on men's childhood experiences, the social-psychological perspective on gender socialization and the feminist perspective on masculinities. The integrative model could then be used as a tentative tool to make hypotheses of how the interaction between conditions at multiple levels results in men's VAW or non-VAW. Thus, the paper first describes the benefits of methodologically integrating these three perspectives and then discuss the used approach that identified a tension within masculinity theory. The paper will develop a critique of Hearn's approach and explain why Messerschmidt's approach are more fruitful. Finally, the combination of gender socialization and childhood experiences are integrated with the masculinity perspective in a model that generates theoretically new masculinity positions alongside Connell's ${ }^{11}$, Connell \& Messerschmidt's ${ }^{12}$ ideal-types: complicit, marginalized and subordinated masculinity. In summary, the integrated model should work against tendencies both towards an idealistic, constructivist approach ${ }^{13}$ and structural determinism (i.e. Connell, Messerschmidt) within the masculinity perspective. As well as towards the structural determinism that is present within the childhood- and the gendersocialization perspectives.

\section{The masculinity approach within feminism}

To highlight this approach, in the next two sections the two general approaches within feminist-oriented masculinity studies will be discussed:

a. The rationalist-constructivist approach that emphasizes the ability of men to construct their own type of masculine identity.

b. The power approach that emphasizes the structures within society that induce men's violent behavior.

The rationalist-constructivist approach: First the paper intends to clarify its ontological positioning in relation to masculinity theory and will therefore build on Elias ${ }^{13}$ figuration perspective as he strives to bridge reductionist explanations of the individual and the society. His approach is of help in addressing the contradiction between a constructivist masculinity theory and the determinism in psychological theories on childhood experiences and gender socialization theories. We need to better understand whether - and if so why - non-violent men's characteristics and way of life differ from those of violent men. In contrast to structuralist approaches, rationalist-constructivist masculinity theorists, such as Hearn, ${ }^{11-15}$ emphasize how men consciously construct their own masculinity and choose to use VAW. Hearn ${ }^{15}$ argues that there are risks associated with the highlighting of psychological causes as explanations for men's VAW. These approaches may be used as excuses for men's VAW and by men advantaged by patriarchy, as a means of avoiding taking responsibility for their VAW. In contrast, there are risks in focusing on men's rational choice, because such an approach tends to underestimate the interdependency between the individual and society. ${ }^{13}$ The rationalist perspective also tends to downplay the importance of economic, social and cultural power structures as well as resource-poor men's limited ability to choose and take full responsibility for how they are doing masculinity. Whilst Hearn ${ }^{15}$ bases his perspective on the premise that men's dominance and VAW is deliberate and rational in order to maintain power over women, scholars such as Scheff \& Retzinger, ${ }^{16}$ Gilligan, ${ }^{17}$ Brown, ${ }^{18}$ and Walker $\&$ Bright ${ }^{19}$ argue that feelings rather than rational calculations play a central role in explaining men's VAW. Also, masculinity researchers, such as Seidler, ${ }^{20}$ point out how the postulation of men as cognitive and rational defenders of patriarchy ignores knowledge about men's emotional losses and suffering in patriarchy. Rather than taking into account these emotional elements, Hearn ${ }^{14-21}$ further argues that men can change their behavior if they are better educated, so that they can make more informed choices. Thus, in his view men's VAW is a problem of responsibility and training, so men could change their behavior through education and by organizing themselves against violence. There are reason to believe that education can help and that it is important for men to learn to take responsibility, but there is a risk that the unjust power structures that produce men's VAW become mystified when one relies on an individual-level solution to the problem. Research by empiricists such as Smith, ${ }^{22,23}$ Gelles $^{24}$ and Flood \& Pease ${ }^{25}$ shows that men, who commit VAW often suffer from 
a lack of economic, social and/or cultural resources. Moreover, they have often lived through patriarchal socialization; have often had violent childhood experiences and have often suffered and witnessed more violence compared with socioeconomically advantaged groups of men. The relationship between childhood experiences and violent forms of masculinity has some support from empirical studies. For example, Mathews et al., ${ }^{26}$ describe how men suffering from their traumatic childhood experiences use violent forms of masculinity to conquer power and respect when they feel powerless and unloved. The paper make use of Elias ${ }^{13}$ relational figuration perspective; since it provides strategies for overcoming the antinomy of methodological individualism and collectivism, the tendency to explain VAW either only on the individual level or only on the structural. Thus Elias figuration perspective is helpful in order to avoid obscuring the interdependent power relations between men using VAW and men who are non-violent. The reason men use VAW is thus explained through their interdependency with non-violent men and as an integral part of the reproduction of both the power of established men and the impotence of marginalized men. From this perspective, it becomes impossible to explain VAW with mere reference to individual characteristics or conscious choice. Connell's ${ }^{11}$ discussion of the hierarchy of men, constructed under hegemonic masculinity, and Messerschmidt's ${ }^{27,28}$ description of marginalized men, are based on the same relational ontology as the figuration perspective. Thus, VAW has to do with.

A. The limitations men suffer from being economically, socially and culturally subordinated to men with greater resources;

\section{B. To differences in childhood experiences; and}

\section{To their socialization as over- or subordinated.}

If we apply Elias ${ }^{13}$ relational/figurational perspective to a normal society characterized by asymmetrical power relations between men, it is likely that the VAW marginalized men, could form the foundation for essentialist stereotypes against them among non-violent men. Such claims can be misused as explanations of men's VAW and can contribute to both discrimination and self-stigmatization processes. This, in turn, obscures the understanding of the structural inequalities that may limit marginalized men's possibilities to reject dominance and VAW as part of their masculinity construction. The larger the class differences are, the fewer opportunities there are for marginalized men to construct their masculinity with conventional resources. From this perspective, the presence or absence of VAW is highly influenced by one's access to, or exclusion from, economic, social and cultural resources. In contrast to the approach that reduces explanations of men's VAW to individual psychological characteristics; it is argued that violent men's individual characteristics are formed as a result of their sharing similar economic, social and cultural experiences. Scholars, such as Smith, ${ }^{22,23}$ have previously concluded that men with low education, income and low-status jobs more often exhibit a patriarchal ideology, and that men with these characteristics are more likely to use VAW than other men. Similarly, Gelles, ${ }^{24}$ as well as other empiricists, later verify that unemployed men and men with lower income exert more VAW than men with employment and higher income. Besides VAW, violence against other men, street crime, drugrelated crime, drug problems and mental disorders is correlated to men being in low socioeconomic positions ${ }^{3-30}$.

The structural-power approach within masculinity studies: In contrast to the actor-based approach, that explains men's VAW as a rational choice, within masculinity studies, other authors have emphasized power relations based on class and other social structures.
Connell, ${ }^{11-31}$ Connell \& Messerschmidt ${ }^{12-32}$ illustrate with the concept of hegemonic masculinity how the relationship between different groups of men and between men and women together reproduces and reifies patriarchy. According to Connell, ${ }^{11}$ masculinity exists within a hierarchy of masculinities. The hegemonic form of masculinity is characterized by contemporary male cultural heroes: astronauts, sports stars, movie stars, politicians and business leaders. The legitimization of the dominant and functional ideal image of man occurs when both sexes accept and submit to it. According to Connell's hegemonic perspective, ${ }^{11}$ men's access to power can be divided into three ideal-types: complicit, marginalized and subordinated. Complicit masculinity profits from that the continued existence of patriarchy. Those with complicit access to power can conserve the power structure without themselves being violent. Those men with marginalized masculinity are poor in both power and resources. They are mainly unemployed, low-paid, unskilled, ethnic minorities, drug addicts or ill, and do not live up to a conventional hegemonic masculinity. Marginalized men without a normal advantage over women as breadwinner become more patriarchal and stereotypical in their attitudes, with little space to express "weakness" and femininity. Those with subordinated masculinity include homosexual men and men with sexualities that are in opposition to the hetero-normative heteropatriarchy. With a critical perspective on hegemony's implications for class and ethnically marginalized men, Messerschmidt ${ }^{27-33}$ argues that criminal activity and VAW become part of their "doing masculinity". ${ }^{27}$ Since violence has been elevated and reified as a central part of the hegemonic masculinity, the internalization of violence could also become a part of the normal masculinity. The emergence of strain (i.e. the lower classes' frustration and anger of being unable to achieve certain socioeconomic goals, ${ }^{34}$ between goals and the availability of resources, force resource-poor marginalized men to seek alternative masculine-validating resources. This tension between ends and means is ultimately a consequence of the inequality that exists under capitalism, where men's violence is explained not only by men's defense of their position towards women, but also in relation to each other in a hierarchy of men. Crime becomes both a way for men to separate themselves from the feminine as well as a way to restore their manhood. Thus, Messerschmidt ${ }^{28}$ argues that even rape can be used as a status-enhancing resource for boys who are unable to live up to the requirements for conventional masculinity. It is not only masculinity researchers, who have related structural inequalities to violence. The hate-crime researcher Perry, ${ }^{35}$ for example, argues that inequality drives marginalized people into "doing difference" (i.e. becoming someone important, being remembered). Chesney-Lind \& Hagedorn $^{36}$ explain how unequal and exclusionary American society propels female gangs as a status-enhancing agent for girls doing gender. DeKeseredy \& Schwartz ${ }^{37}$ relate men's VAW to structural change in the U.S. and unemployed men's stress over not being able to live up to the traditional breadwinner role. Krienert ${ }^{38}$ shows in a quantitative empirical study that a relationship exists between low access to socially acceptable methods for achieving a conventional masculinity and an increased involvement in crime. Despite the merits of the resource perspective, this perspective becomes one-dimensional if not complimented with other approaches. The reason being that it mainly highlights VAW as the result of strain/anomie among culturally influenced masculinity norms and various men's access to resources for doing masculinity; in doing so it ignores childhood experiences and primary socialization. This model shows that in a society that offers high possibilities for men doing masculinity with conventional means, men with high access to economic, social and cultural resources of doing masculinity will naturally strive to distance themselves from VAW as part of their masculinity construction. In a society that offers 
low possibilities for men doing masculinity with conventional means and where men have low access to economic, social and cultural resources, VAW presents one of few ways for men to reinforce their masculinity. In a society where men's access to economic, social and cultural resources is high, but offers few opportunities for men doing masculinity with conventional means, VAW could be explained by its traditional or cultural meaning as a sanction that reminds both women and men about a patriarchal norm. Finally, for those men who have low access to economic, social and cultural resources, VAW could become a defense against a failed masculinity (Table 1). If variations in gender socialization and childhood experiences are taken into account, it becomes possible to develop an understanding of the logic behind various masculinity positions in relation to VAW and a more developed conceptual framework for further research is also offered.

Table I The one-dimensional perspective of men's VAW or non-VAW as the outcome of the integration of the resources available in the men's masculinity position and the society's ability to offer men conventional means of doing masculinity

\begin{tabular}{|c|c|c|c|c|}
\hline \multirow{5}{*}{$\begin{array}{l}\text { The society's ability to } \\
\text { offer possibilities for men } \\
\text { doing masculinity with } \\
\text { conventional means }\end{array}$} & \multicolumn{4}{|c|}{$\begin{array}{l}\text { The men's masculinity position as } \\
\text { similar to their individual access to } \\
\text { economic, social and cultural resources } \\
\text { of doing masculinity }\end{array}$} \\
\hline & & Low & Medium & High \\
\hline & 总 & $\begin{array}{l}\text { Men's VAW is used } \\
\text { when they failed doing } \\
\text { conventional masculinity }\end{array}$ & $\uparrow$ & $\begin{array}{l}\text { Men's use of VAW is } \\
\text { unnecessary and it is } \\
\text { stigmatizing as it lowers } \\
\text { their status. }\end{array}$ \\
\hline & 咅 & $\leftarrow$ & $\begin{array}{c}\text { Men's VAW is situational and } \\
\text { contextualized as there is alternatives } \\
\text { present }\end{array}$ & $\rightarrow$ \\
\hline & 3 & $\begin{array}{l}\text { There is pressure on men } \\
\text { to use VAW as it is one of } \\
\text { few ways of doing gender }\end{array}$ & $\downarrow$ & $\begin{array}{c}\text { Men's use of VAW is } \\
\text { traditionalized and has } \\
\text { a symbolic or cultural } \\
\text { meaning }\end{array}$ \\
\hline
\end{tabular}

Table $\mathbf{2}$ The hypothesized curvilinear relationship between different forms of socialization, childhood experiences and risks for men's VAW

\begin{tabular}{|c|c|c|c|}
\cline { 2 - 4 } \multicolumn{1}{c|}{} & $\begin{array}{c}\text { Harmonic and nonviolent childhood } \\
\text { experiences }\end{array}$ & $\begin{array}{c}\text { Ambivalent childhood } \\
\text { experiences }\end{array}$ & $\begin{array}{c}\text { Violent childhood } \\
\text { experiences }\end{array}$ \\
\hline Patriarchal socialization & High & Higher & Highest risk VAW \\
\hline $\begin{array}{c}\text { Ambivalent } \\
\text { socialization }\end{array}$ & Low & Medium \\
\hline Egalitarian socialization & \multicolumn{2}{|c|}{ Lowest risk of VAW } & Low \\
\hline \multicolumn{2}{|c|}{ Scale: Lowest - Lower - Low - Medium - High - Higher - Highest } \\
\hline
\end{tabular}

\section{The psychological explanation of Men's VAW}

Men and women's experiences of violence and abuse in childhood are another area that has been repeatedly linked to men's VAW and often related to as the intergenerational transmission (IGT) of violence. According to previous empirical studies by Fagan et al., ${ }^{39}$ Smith, ${ }^{23}$ Gondolf, ${ }^{29}$ Markowitz, ${ }^{40}$ Delsol et al., ${ }^{41}$ when children witness violence in the family, even when they are not directly exposed to it, the violent behavior is transmitted through generations of males in the family and accepted as a norm by the females in the family. The experience of violence in childhood of both sexes is important in explaining men's VAW, as children learn that violence is a legitimate way of solving conflicts. Straus ${ }^{42}$ argue that men's witnessing of violence in childhood and their being victims of it can be related to their own VAW. Gilligan, ${ }^{17}$ Scheff,,${ }^{16}$ Brown, ${ }^{18}$ Maltingly \& Straus, ${ }^{43}$ Wei \& Brackley ${ }^{44}$ and Voorthuis et al. ${ }^{45}$ emphasize the relationship between having been a victim of both physical and psychological violence (abuse in childhood from one or both parents and/or witnessed violence against the mother and increased sensitivity to situations as an adult where one relives shameful experiences of being unloved: isolated, rejected, neglected, abandoned). According to Walker \& Bright, ${ }^{19}$ abuse in childhood leads to lower self-respect and induces men to act aggressively to save face and defend their selfrespect when conflicts arise. Earlier research by Telch \& Lindquist, ${ }^{22-46}$ Pease, ${ }^{47}$ and Kitzman et al., ${ }^{48}$ concludes that a combination of

a. Patriarchal socialization and

b. Experiences of violence against the mother in the family, teaches boys that violence is a legitimate way of dealing with conflicts with women.

Campbel1 ${ }^{49}$ further argues that the risk of violence increases when the boy learns that his father's VAW serves as a status-enhancing problem-solving method. To summarize, IGT is generally welldocumented, as there is a strong correlation between having witnessed/ been a victim of violence and holding positive attitudes towards violence and exercising violence..$^{25}$ In the paper it is argued that since VAW appears to be most common in socially disadvantaged groups, 
the witnessing of violence and exposure to violence by children in those groups must also be extensive and cause vicious cycles of IGT. Men living in a patriarchal culture, according to Seidler ${ }^{50}$ learn to take self-control, to oppress emotions associated with femininity and to focus on rational thinking. Thus, there is reason to believe that when experiencing victimization and fear, men transform their feelings of vulnerability and shame into anger and aggression. ${ }^{16-52}$ This link between masculinity, emotional fear, shame and anger, has been confirmed by Jakupcak et al., ${ }^{53}$ who used a social learning perspective. Although this perspective is well-documented, it lacks a macrosociological framework that explains how childhood experiences are influenced by power relationships between classes and how different childhood experiences can be formed in a single class context.

\section{Feminist research on socialization and Men's VAW}

Now we return to another area of feminist research on VAW: the socialization approach. The previous psychological model, in Table 1, is integrated with an expanded model that includes gender socialization. The relationship between men's socialization, internalization of a patriarchal ideology and VAW is well-documented in previous feminist research on socialization. A patriarchal ideology, according to Yllo, ${ }^{54,55}$ relates to whether the man has both the final say and authority when it comes to important matters, and violence against women has a tendency to increase in countries during periods in which women's status is rapidly improving, as this process challenges the men's patriarchal benefits. According to Smith, ${ }^{22}$ there is a relationship between patriarchal expectations of women and VAW. Smith ${ }^{23}$ claims that the belief in patriarchal ideology induces men to decide over women - including their work life, social life and sexuality. Dobash \& Dobash ${ }^{56}$ argue that patriarchal ideology is expressed through men's control and isolation of the woman, and that VAW is used as a sanction against disobedient women. Flood \& Pease ${ }^{25}$ argue that previous research substantiated the fact that men's assertion of distinct gender roles is the strongest predicting variable to men's VAW. And that socially marginalized men, who accept a patriarchal ideology and a traditional gender perception, are also more positive toward VAW, use more VAW, show less empathy and blame women more for their violence. Children who are socialized early in an environment characterized by a patriarchal ideology also internalize values that make them believe that men have more rights than women. This perspective constructs socialization as being the dependent variable to the patriarchate at the societal level, but it does not relate socialization to a macro-sociological theory that can explain how attitudes are related to the economic, social and cultural resources that men have access to.

\section{The integration of psychological and socialization approaches into the concept of family resources}

After demonstrating the shortcomings of each perspective, where the common denominator is the tendency to reduce the understanding of VAW to a single explanatory cause or a dualistic relationship between factors, I will now proceed by developing a new model. The first step involves the integration of research on violent childhood experiences and on men's VAW with research on the significance of patriarchal gender socialization and men's VAW. With this combination, it is possible to discuss what types of childhood experiences and socialization play the strongest role in inducing men to be either violent or non-violent towards women. Research on violent men has generally ignored non-violent men. Consequently, theoretical discussions have neglected the relationship between the two groups; thus this model seeks to illuminate qualities that also categorize non-violent men. Childhood experiences are categorized into three groups: a. harmonic/non-violent, where the boy was neither subjected to nor witnessed violence or abuse and insults, but instead experienced safety and security;

b. ambivalent, where different types of violence may have been present but were rare; and

c. Violent, where the boy suffered from violence, serious violations and abuse, witnessed violence a

d. Egalitarian, where the boy learned that VAW is unacceptable and that one should support equality and equal gender roles.

e. Ambivalent, where the boy faced an inconsistent mix of a patriarchal and egalitarian upbringing.

f. Patriarchal, where the boy generally learned that men are superior to women and that men have the right to control women's personal finances, sexuality and socializing, and that violence may be considered as a permissible conflict resolution.

\section{g. gainst the mother/relatives and learned to hide emotions.}

\section{Socialization is divided into three main types:}

Table 2 shows how the different combinations of childhood experiences and socialization could logically influence men's VAW. The combination that theoretically poses the highest risk for men's VAW combines exposure to violence in childhood with patriarchal socialization. The negation of this position, through the combination of harmonic/nonviolent childhood experiences and egalitarian socialization, is logically assumed to give the lowest risk for VAW. The ambivalent position is complex, as it includes six combinations that make hypotheses about the risk of men's VAW difficult. In light of previous research, ${ }^{25}$ men's VAW is assumed to increase curvilinear. Since the model in its present form contains too many variations, which is a result of the essential highlighting of the ambivalent position, the various combinations are broken down into three main groups of high, medium or low access to positive family resources (Table 3). The combination of egalitarian socialization and harmonic/ non-violent childhood experiences is categorized as high access to positive family resources. This ideal-typical concept of high access to positive family resources represents a combination that according to previous research is not associated with men's VAW. The combination of patriarchal socialization and violent childhood experiences is categorized as low access to positive family resources, since previous research has demonstrated a strong relation to VAW. The positions that are created by having ambivalent socialization and any of the three forms of childhood experiences that are formed by ambivalent childhood experiences are categorized as medium access to positive family resources. These categories have the advantage of enabling us to represent non-violent and ambivalent men, who in previous research have been marginalized empirically. Since the model is theory-driven and ideal-typical, it is difficult to describe in detail the characteristics of the ambivalent group of men, where socialization and childhood experiences are inconsistent with each other, although the model does demonstrate a problem that research must address. Although the ambivalent position demonstrates the problems that come with using non-dichotomizing models, it is argued that it is nevertheless important to show that this kind of combination should be kept in mind as it probably corresponds with what could be quite ordinary experiences of family violence. This simplification, which combines psychological factors with socialization, lays the foundation for going one step further, where access to economic and cultural resources is taken into account. 
Table 3 Hypothesized ideal-typical model illustrating the reduction of nine types of combinations between childhood experiences and socialization into three forms of family resources

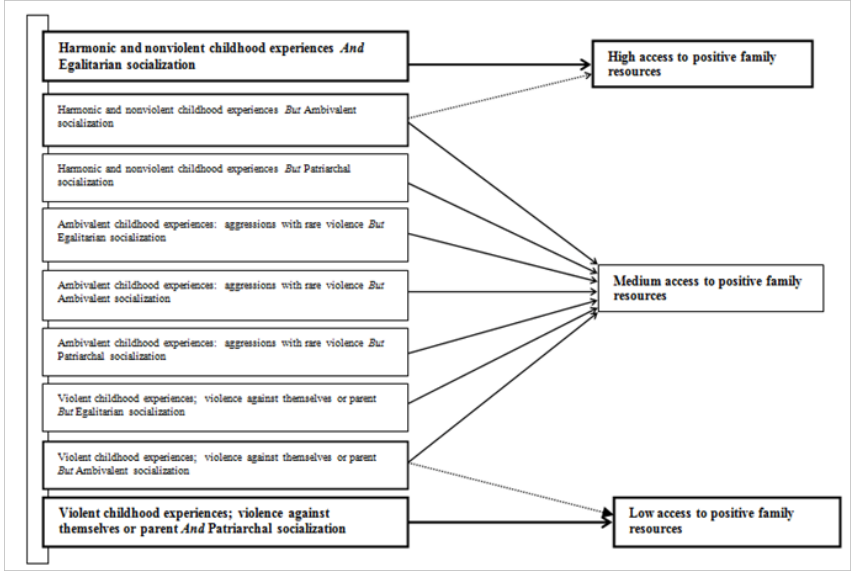

Integrating access to family resources with access to hegemonic masculinity resources

The next step is to integrate the derivatives from each research tradition-the psychological, the gender-socialization and the masculinity - with each other. As this integrative model puts violent and non-violent in a figurative power relation, where one group's power and the other's powerlessness are related to each other, it generally increases our knowledge about the macro relational aspects of VAW. In this tentative model, research from the different theoretical traditions is weighted equally, even though in reality the traditions has a greatly different empirical basis for its conclusions, which becomes an empirical question to address later.

\section{It is argued that there is an interaction between}

i. Men's internalized structures that are the result of their childhood experiences

\section{ii. Men's gender socialization and}

iii. The social structures that limit or enable men's masculinity construction. Similarly, childhood experiences and gender socialization are related to the different access of resources that one has in doing masculinity.

To summarize, the strength of the masculinity approach is that it shows that men not only find themselves in a power relationship with women, they also find themselves within a hierarchy of men. In this hierarchy, men who are unable to live up to the standards of success with conventional means could feel pressure to choose crime, violence and VAW to gain status in hegemonic masculinity. The weakness of this approach is its one-dimensionality. It only highlights the strain/ anomie between masculinity norms and men's access to resources for doing masculinity and lacks a deeper understanding of how childhood experiences and socialization affect men's development of masculinity and their use of VAW. Meanwhile, the strength of the childhood-experience perspective is that it explains how important the experience of having been a victim of violence and abuse, and of witnessing violence is to men's VAW. Men's reliving of negative childhood experiences of being unloved is related to aggressions and VAW. This perspective also illustrates how violence is learned and how intergenerational attitudes are transmitted. The weakness of the perspective is that it does not relate to structural factors that may enhance or counteract VAW by adult men. The strength of the patriarchal gender socialization perspective on men's VAW is that it has accumulated knowledge on how men are affected by being socialized in a patriarchal context, where women are regarded as subordinate, where men are in charge of women, where men are considered as essential/biologically diverse to women and where women are regarded as possessions. This attitude towards women justifies men's social, professional and sexual dominance. The weakness of this perspective is its danger of falling into an ecological fallacy, as it reduces the explanation of VAW to a more or less imprecise patriarchy. The concept family resources, which this article introduces, bridge some of the contradictions between the psychological level (i.e. childhood experiences) and the social-psychological level (i.e. gender role socialization). It does so by making the interaction between enabling and restricting conditions at the two levels visible. This concept includes the combination of violent childhood experiences and patriarchal socialization, which previous research has shown to be a strong predictor of men's VAW. In addition, though, it also defines other positions that are characterized by a harmonic/non-violent and egalitarian socialization. Furthermore, it also defines interesting and elusive intermediate forms that give an ambivalent position. A shortcoming of the concept of family resources is that it only combines the psychological and social-psychological level. It also lacks a relationship to macro-structures such as class and ethnicity that affect men's access to socioeconomic and cultural resources doing masculinity. Another disadvantage is that this concept cannot shed light on how all the positions, within the position of medium access to positive family resources, are manifested. A synthesis of psychology (i.e. childhood experiences), social psychology (i.e. gender socialization) in the form of family resources, and structural aspects (i.e. socioeconomic and cultural resources) is essential for improving our understanding of the figurative power of the relationship between violent and non-violent men. Structures such as class and ethnicity can both counteract and reinforce the qualities that men carry with them in the form of family resources. If the researcher lacks access to all three levels, he or she cannot understand how these factors interact with men's VAW or non-VAW. The integration of these levels not only contributes to a theoretical and methodological development of a new model, but it also allows one to integrate Connell's three main masculinity positions into the model. Thus, this model takes into account his classification of complicit, marginalized and subordinated masculinities. The reduction of the factors (Table $2 \& 3$ ) into the three main types of "access to positive family resources" thus enables us to integrate Messerschmidt' ${ }^{27,28}$ critical perspective, in which a central starting point is men's access to socioeconomic resources for doing masculinity. When men's access to positive family resources and their access too socioeconomically and cultural resources are combined, it is possible to discuss whether or not there are several different practices of "doing masculinity" in addition to the idealtypical forms that Connell, ${ }^{11}$ Connell \& Messerschmidt ${ }^{12}$ formulated (Table 4). In the horizontal dimension, men can be hegemonic, complicit or marginalized based on their access to economic, social and cultural resources. In the vertical dimension, men can be profeminist, ambivalent or patriarchal, based on their access to positive family resources. Based on these two dimensions, it is also possible to hypothetically analyze the risk of VAW for people in each of these positions, in relation to previous research.

\section{Multiple forms of marginalized masculinities}

This section begins with a discussion on the different derived forms of marginalized masculinities. They can be seen in the column furthest to the right in Table 4. Men in this group lack socioeconomic and cultural resources. Furthermore, they do not live up to the conventional standards of hegemonic masculinity. This could be 
because they lack a job, are poorly educated, are not law-abiding or are not drug-free. As marginalized men normally have experienced subordination, they should develop an empathic understanding of what oppression means. At the same time, men in this position are often supporters of patriarchal attitudes and statistically use more VAW than other groups.

Patriarchal marginalized masculinity with highest risk VAW: This group includes men with low access to economic, social and cultural resources. These men had a patriarchal upbringing and violent childhood experiences. This violence was directed at them or their relatives, leaving them with low access to positive family resources. These factors combined give them the highest risk of VAW. Since men in this position generally have small socio-economic resources, they could feel forced to use unconventional means, such as VAW, as a means of gaining status as men. This position could idealtypically include poor, low-income, ethnic, sick, drug-addicted and criminal men in a weak social position.

Ambivalent marginalized masculinity with high risk of VAW: This group includes men with low access to economic, social and cultural resources. Through a mixture of different intermediate forms of egalitarian/patriarchal socialization and harmonious/violent childhood experiences (Table 3), they have medium access to positive family resources. As this position only gradually differs from the above, it is likely to include similar categories of men.

Pro-feminist marginalized masculinity with low risk of VAW: This group includes men with low access to socioeconomic and cultural resources that benefit from high accessibility to positive family resources as they experienced a harmonic/non-violent childhood and were socialized to have egalitarian values. This position includes men who found a context where they could use their internalized profeminist attitude as a resource in the hegemonic masculinity structure. This position could include men in NGOs (Non-Governmental Organizations) who fight against gender injustices.
Multiple forms of complicit masculinities: The column in the center of Table 4 shows the multiple forms of complicit masculinities consisting of men with high access to socioeconomic resources through their profession and education, and who can use conventional means to reach the status of hegemony.

Patriarchal complicit masculinity with high risk of VAW: This group includes men with medium level access to economic, social and cultural resources and low access to positive family resources as they lived through a patriarchal upbringing and a violent childhood. These men are able to meet the conventional status requirements under the hegemonic masculinity but may be at risk of using violence in shameinducing situations where they relive negative childhood experiences or confront equality-seeking female partners. Men in this position could do masculinity with reference to essentialism/socio-biological arguments ${ }^{57}$ to legitimize the present gender differences. This position could include economically stable but less educated men and men with a patriarchal upbringing and low family resources.

Ambivalent complicit masculinity with medium risk VAW: This includes men with medium access to economic, social and cultural resources, which through a mixture of different intermediate forms of egalitarian and patriarchal socialization and harmonious and violent childhood experiences (Table 3) have medium access to positive family resources. This position is likely to include men similar to those above.

Pro-feministic complicit masculinity with lower risk of VAW: This includes men with medium access to economic, social and cultural resources and with high access to positive family resources as they experienced an egalitarian socialization and a harmonic/non-violent childhood. Men in this group are normally positive towards equality and could ideal-typically include well educated fathers on parental leave, men's networks, pro-gender equality and men organized against violence.

Table 4 The combination of family resources and socioeconomic resources and the generation of new masculinity positions with a proposed risk for VAW

\begin{tabular}{|c|c|c|c|c|}
\hline \multirow{5}{*}{$\begin{array}{l}\text { Access to } \\
\text { positive } \\
\text { family } \\
\text { resources }\end{array}$} & & \multicolumn{3}{|c|}{$\begin{array}{l}\text { Access to economic, social } \\
\text { and cultural resources }\end{array}$} \\
\hline & & High & Medium & Low \\
\hline & High & $\begin{array}{l}\text { Profeministic hegemonic } \\
\text { masculinity: } \\
\text { Lowest risk VAW }\end{array}$ & $\begin{array}{l}\text { Profeministic complicit } \\
\text { masculinity: Lower risk VAW }\end{array}$ & $\begin{array}{l}\text { Profeministic marginalized } \\
\text { Masculinity: Low risk VAW }\end{array}$ \\
\hline & Medium & $\begin{array}{l}\text { Ambivalent hegemonic } \\
\text { masculinity: Lower risk VAW }\end{array}$ & $\begin{array}{c}\text { Ambivalent complicit } \\
\text { masculinity: Medium risk } \\
\text { VAW }\end{array}$ & $\begin{array}{c}\text { Ambivalent marginalized } \\
\text { Masculinity: High risk } \\
\text { VAW }\end{array}$ \\
\hline & Low & $\begin{array}{c}\text { Patriarchal hegemonic } \\
\text { masculinity: Medium risk VAW }\end{array}$ & $\begin{array}{c}\text { Patriarchal complicit } \\
\text { masculinity: High risk VAW }\end{array}$ & $\begin{array}{c}\text { Patriarchal marginalized } \\
\text { Masculinity: Highest risk } \\
\text { VAW }\end{array}$ \\
\hline
\end{tabular}

\section{Multiple forms of hegemonic masculinities}

The first column to the left of Table 4 shows the multiple forms of hegemonic masculinities. By supplementing Connell's ${ }^{11}$ view of hegemonic masculinity with Wright Mills ${ }^{58}$ description of the power elites, the paper emphasizes the importance of male elites in economic, political and cultural institutions who govern and create a hegemony based on egoistic interests. These power elites are idealtypically patriarchal, ambivalent or pro-feministic, or carry incentives to retain or abolish the power differences between men and between men and women. The power elites' approach to the change of norms and institutions-which may increase or decrease men's power over women-is therefore central to our understanding of men's VAW. 
Patriarchal hegemonic masculinity with medium risk VAW: This includes men with very high access to economic, social and cultural resources, but with low access to positive family resources because they experienced a patriarchal upbringing and were exposed to violence during their childhood. This group is categorized by male elites, preserving the patriarchal status quo, who are highly sensitive to situations where their traumatic childhood experiences are relived.

Ambivalent hegemonic masculinity with low risk of VAW: This includes men with high access to economic, political, social and cultural resources that through a mixture of different intermediate forms of egalitarian and patriarchal socialization as well as a mixture of harmonic and violent childhood experiences (Table 3 ) have medium access to positive family resources.

Pro-feminist hegemonic masculinity with lowest risk VAW: This includes men with high access to economic, political, social and cultural resources and to family resources as they experienced an egalitarian socialization and a harmonic/non-violent childhood. This position is limited to men who use their political, economic and cultural resources to change institutions and attitudes towards equality and to reduce men's VAW.

\section{Conclusion}

This integrative model that is suggested is designed to improve the understanding of the relationship between conditions at the level of childhood experience, gender socialization and socioeconomic resources that either cause or counteract VAW. The integration of different research traditions could be used as the starting point for research that aims to unveil the vicious or virtuous circles of power relationships that men find themselves in. The vicious circle is characterized by men who are at the mercy of emotionally hostile, patriarchal and violent gender socialization and who have limited resources to meet the demands of the hegemonic masculinity. Men with few socioeconomic resources are more likely to suffer from shame and want to compensate for this by exercising power over women in intimate relationships. The virtuous circle is characterized by men with great access to both family resources and socioeconomic resources. They have inherited values from their parents that provide excellent resources for both the defense and the conquest of the conventional hegemonic masculinity. Since all societies are characterized by the existence of different classes, an explanation of men's VAW has to relate to the fact that the men in the top and bottom positions are related to each other where the power by the powerful group is dependent on the other group's subordination and powerlessness. The complex ambivalent position in the middle exposes the limitations of dichotomizing explanations of men's VAW and illustrates the importance of combining extensive quantitatively oriented methodologies with qualitative narratives as they make it possible to follow the fate of the individual male. It is reasonable to assume that many men, despite their parents' best intentions to make them supportive of gender equality, have nonetheless experienced an ambivalent socialization, since almost all men while growing up have been influenced by gender stereotypes. In view of the reviewed research, it is reasonable to assume that those men that use VAW have individual childhood experiences that make them more sensitive to situations that remind them of abuse, such as humiliation, abandonment and the feeling of being unloved. Socialization in itself is not a sufficient explanation because most men who have not witnessed violence have objections against engaging in VAW. The main hypotheses coming from the model presented in this article are about where preventive interventions are most crucial: a. If negative experiences during childhood are presumed to be the strongest factor to predict VAW, it follows that a patriarchal socialization and a marginalized masculinity position only results in VAW when harmonic childhood experiences not is a counteracting force.

b. Following the same premise, a violent and abusive childhood can only be counteracted by both an egalitarian socialization and high access to socioeconomic resources guiding ones' masculinity construction. When negative childhood experiences, patriarchal socializations and marginalized masculinity constructions are most common among lower social classes, the best prevention to VAW is a socioeconomic policy that increases equality and social reforms that increase these groups' possibilities to break out of the vicious circles.

\section{Acknowledgments}

None.

\section{Conflicts of interest}

Author declares there are no conflicts of interest.

\section{Funding}

None.

\section{References}

1. United Nations. Say NO UNiTE to End Violence against Women. 2009.

2. Brownridge DA. Violence against women: Vulnerable populations. Routledge, USA. 2009. p.1-302.

3. Dutton DG. Patriarchy and wife assault: The ecological fallacy. Violence and Victims. 1994;9(2):167-182.

4. Dutton DG. Rethinking domestic violence. University of British Columbia Press, Canada. 2006.

5. Crowell NA, Burgess AW. Understanding violence against women. National Academy Press, USA. 1996. p.1-240.

6. O’Neil JM, Harway M. Revised multivariate model explaining men's risk factors for violence against women: theoretical propositions, new hypotheses, and proactive recommendations. In: Harway M \& O'Neil JM (Eds.), What causes men's violence against women, Sage, UK. 1999. p.207-241.

7. Heise LL. Determinants of partner violence in low and middle-income countries: exploring variation in individual and population-level risk. London School of Hygiene \& Tropical Medicine, UK. 2012.

8. Ali PA, Naylor PB. Intimate partner violence: A narrative review of the feminist, social and ecological explanations for its causation. Aggression and Violent Behavior. 2013;18:611-619.

9. Sayer A. Method in social science. A realist approach. (1st edn), Routledge, UK. 1992. p.1-326.

10. Craig CD, Sprang G. Trauma exposure and child abuse potential: Investigating the cycle of violence. The American Journal of Orthopsychiatry. 2007;77(2):296-305.

11. Connell RW. Masculinities, University of California Press, Berkeley, USA. 1995. p.1-349.

12. Connell RW, Messerschmidt J. Hegemonic masculinity-rethinking the concept. Gender and society. 2005;19(6):829-859.

13. Elias N. The established and the outsider. A sociological enquiry into community problems. Sage, UK. 1994. 
14. Hearn J. Men will be men. The ambiguity of mens support for men's violence to known women. In: Popay J Hearn, et al. (Eds.), Men gender divisions and welfare, Routledge, USA. 1998. p.147-180.

15. Hearn J. The Violences of Men. Sage Publications, London. 1998.

16. Scheff TJ. Male emotions and violence: A case study. Human Relations. 2003;56(6):727-749.

17. Gilligan J. Shame, guilt and violence. Social Research. 2003;70(4):1149-1180.

18. Brown J. Shame and domestic violence: Treatment perspectives for perpetrators from self psychology and affect theory. Sexual and Relationship Therapy . 2004;19:39-56.

19. Walker JS, Bright JA. False inflated self-esteem and violence: a systematic review and cognitive model. The Journal of Forensic Psychiatry \& Psychology. 2009;20(1):1-32.

20. Seidler VJ. Unreasonable men, masculinity and social theory. Routledge, USA. 1994

21. Hearn J. Educating men about violence against women. Women Studies Quarterly. 1999;27:140-151.

22. Smith MD. Sociodemographic risk-factors in wife abuse: Results from a survey of Toronto. Canadian Journal of Sociology. 1990;15(1):39-58.

23. Smith MD. Patriarchal ideology and wife beating: a test of a feminist hypothesis. Violence Vict. 1990;5(4):257-273.

24. Gelles RJ. Male offenders. Our understanding from the data. In: M. Harway \& J.M. O'Neil (Eds.), What causes men's violence against women? Sage Publications, UK. 1999. p.36-48.

25. Flood M, Pease B. Factors influencing attitudes to violence against women. Trauma Violence \& Abuse. 2009;10(2):125-142.

26. Mathews S, Jewkes R, Abrahams N. I had a hard life: Exploring childhood adversity in the shaping of masculinities among men who killed an intimate partner in South Africa. British Journal of Criminology. 2011;51(6):960-977.

27. Messerschmidt JW. Masculinities and Crime. Rowman \& Littlefield, Maryland, USA. 1993. p.1-256.

28. Messerschmidt JW. Nine lives: Adolescent masculinities, the body, and violence. Rowman \& Littlefield, Maryland, USA. 2000. p.1-168.

29. Gondolf E. Discussion of violence in psychiatric evaluations. Journal of Interpersonal Violence. 1992;7(3):334-349.

30. Altonen M, Kivivuori J, Martikainen P, et al. Socioeconomic status and criminality as predictors of male violence. British Journal of Criminology. 2012;52(6):1192-1211.

31. Connell RW. Gender and power: society, the person, and sexual politics. Stanford University Press, USA. 1987. p.1-352.

32. Messerschmidt JW. Engendering gendered knowledge: Assessing the academic appropriation of hegemonic masculinity. Men and Masculinities. 2012;15(1):56-76.

33. Messerschmidt JW. Crime as structured action: gender, race, class and crime in the making. Sage Publications, USA. 1997. p.1-144.

34. Merton RK. Social Theory and Social Structure. Free Press, New York, USA. 1968.

35. Perry B. In the name of hate: Understanding hates crime. (1st edn), Routledge, USA. 2001. p.1-288.

36. Chesney Lind M, Hagedorn JM. Female gangs in America: Essays on girls, gangs and gender. (1st edn), Lakeview press, Chicago, USA. 1999. p.1-368.

37. DeKeseredy WS, Schwartz, MD. Dangerous exits: Escaping abusive relationships in rural America. Rutgers University Press, USA. 2009. p. $1-272$.

38. Krienert JL. Masculinity and crime: A quantitative exploration of Messerschmidt's hypothesis. Electric Journal of Sociology. 2003;17(2):1-19.

39. Fagan JA, Stewart DK, Hansen KV. Violent men or violent husbands? Background factors and situational factors. In: Finkelhorn RJ, et al. (Eds.), The Dark side of Families. Sage, UK. 1983. p.49-67.

40. Markowitz FE. Attitudes and family violence: Linking intergenerational and cultural theories. Journal of Family Violence. 2001;16(2):205-218.

41. Delsol C, Margolin G, John RS. A typology of martially violent men and correlates of violence in a community sample. Journal of marriage \& family. 2003;65(3):635-652.

42. Straus MA. Children as witnesses to marital violence: A risk factor of life-long problems among a national representative study of American men and woman. In: Schwartz DF (Ed.), Children and violence: Report of the twenty-third Ross roundtable on critical approaches to common pediatric problems, Ross Laboratories, USA. 1992 . P. 98-109.

43. Maltingly MJ, Straus MA. Violence Socialization and Approval of Violence: A World Perspective on Gender Differences and American Violence, Paper presented at the annual meeting if the American Society of Criminology, St Louis, USA. 2008. p.1-25.

44. Wei CC, Brackley M. Men who experienced Violence or Trauma as children or adolecents and who used violence in their intimate relationships. Issues in Mental Health Nursing. 2010;31(8):495-506.

45. Voorthuis A, Bhandari R, Out D, et al. Childhood Maltreatment Experiences and Child Abuse Potential: Temperamental Sensitivity as Moderator? Journal of Family Violence. 2014;29(7):749-756.

46. Telch CF, Lindquist CU. Violent versus non-violent couples: A comparison of patterns. Psychotherapy. 1984;21:242-248.

47. Pease B. Developing pro feminist practice with men in social work Critical Social Work. 2001;2(1):1-8.

48. Kitzmann KM, Gaylord NK, Holt AR, et al. Child witnesses to domestic violence: A meta-analytic review. J Consult Clin Psychol. 2003;71(2):339-352.

49. Campbell A. Out of control: Men women and aggression. Pandora, London, UK. 1993.

50. Seidler VJ. Rediscovering masculinity. Reason, language and sexuality. Routledge, UK. 1989.

51. Scheff TJ. Aggression, Hypermasculine Emotions and Relations: the Silence/Violence Pattern, Irish Journal of Sociology. 2006;15(1):24-37.

52. Scheff TJ, Retzinger SM. Emotions and violence. Shame and rage in destructive conflicts. iUniverse, USA. 2001. p.1-207.

53. Jakupcak M, Tull MT, Roemert L. Maculinity, shame and fear of emotions as predictors of men's expressions of anger and hostility. Psychology of Men \& Masculinity. 2005;6(4):275-284.

54. Yllo KA. Sexual equality and violence against wives in American states. Journal of Comparative Family Studies. 1983;14:67-86.

55. Yllo KA. The status of women, marital equality, and violence against wives. Journal of Family Issues. 1984;5(3):307-320.

56. Dobash RP, Dobash RE (1995) Reflections on findings from the violence against women survey. Canadian Journal of Criminology 37: 457-484

57. Goldberg S. The logic of patriarchy, Humanities, Social Sciences and Law. 1999; 17:53-69.

58. Wright Mills C. The power elite. Oxford Press, Oxford, USA. 2000 p. $1-448$. 